\title{
Prevention and Management of Non-Communicable Disease: The IOC Consensus Statement, Lausanne 2013
}

\author{
Gordon O. Matheson • Martin Klügl · Lars Engebretsen · Fredrik Bendiksen • Steven N. Blair • Mats Börjesson • \\ Richard Budgett • Wayne Derman · Uğur Erdener • John P. A. Ioannidis • Karim M. Khan • Rodrigo Martinez • \\ Willem van Mechelen • Margo Mountjoy • Robert E. Sallis • Martin Schwellnus • Rebecca Shultz • \\ Torbjørn Soligard · Kathrin Steffen $\cdot$ Carl Johan Sundberg • Richard Weiler • Arne Ljungqvist
}

Published online: 16 October 2013

(C) Springer International Publishing Switzerland 2013

\begin{abstract}
Morbidity and mortality from preventable, noncommunicable chronic disease (NCD) threatens the health of our populations and our economies. The accumulation of vast amounts of scientific knowledge has done little to change this. New and innovative thinking is essential to foster new creative approaches that leverage and integrate evidence through the support of big data, technology, and design thinking. The purpose of this paper is to summarize the results of a consensus meeting on NCD prevention sponsored by the International Olympic Committee (IOC) in April, 2013. Within the context of advocacy for multifaceted systems change, the IOC's focus is to create solutions that gain traction within health care systems. The
\end{abstract}

G. O. Matheson · R. Shultz

Division of Sports Medicine, Department of Orthopaedic

Surgery, Stanford University School of Medicine, Stanford, USA

G. O. Matheson - R. Shultz

Human Performance Laboratory, Department of Orthopaedic

Surgery, Stanford University School of Medicine, Stanford, USA

G. O. Matheson $(\bowtie)$

Sports Medicine Center, 341 Galvez Street, Stanford, CA 94305, USA

e-mail: gord@stanford.edu

\section{Klügl}

Department of Healthy Policy and Management, Harvard

University, Boston, USA

L. Engebretsen · F. Bendiksen · K. Steffen

Department of Sports Medicine, Oslo Sports Trauma Research

Center, Norwegian School of Sports Science, Oslo, Norway

L. Engebretsen · R. Budgett · U. Erdener · T. Soligard ·

A. Ljungqvist

Medical and Scientific Department, International Olympic

Committee, Lausanne, Switzerland group of participants attending the meeting achieved consensus on a strategy for the prevention and management of chronic disease that includes the following:

1. Focus on behavioural change as the core component of all clinical programs for the prevention and management of chronic disease.

2. Establish actual centres to design, implement, study, and improve preventive programs for chronic disease.

3. Use human-centered design in the creation of prevention programs with an inclination to action, rapid prototyping and multiple iterations.

4. Extend the knowledge and skills of Sports and Exercise Medicine (SEM) professionals to build new

L. Engebretsen

Orthopaedic Center, Ullevål University Hospital, University of Oslo, Oslo, Norway

S. N. Blair

Departments of Exercise Science and Epidemiology and Biostatistics, Arnold School of Public Health, University of South Carolina, Columbia, USA

M. Börjesson

Åstrands Laboratory, The Swedish School of Sport and Health

Sciences, Stockholm, Sweden

M. Börjesson

Department of Cardiology, Karolinska University Hospital,

Stockholm, Sweden

W. Derman · W. van Mechelen · M. Schwellnus

Clinical Sports and Exercise Medicine Research Group, UCT/ MRC Research Unit for Exercise Science and Sports Medicine, Department of Human Biology, University of Cape Town, Cape Town, South Africa 
programs for the prevention and treatment of chronic disease focused on physical activity, diet and lifestyle.

5. Mobilize resources and leverage networks to scale and distribute programs of prevention.

True innovation lies in the ability to align thinking around these core strategies to ensure successful implementation of NCD prevention and management programs within health care. The IOC and SEM community are in an ideal position to lead this disruptive change. The outcome of the consensus meeting was the creation of the IOC NonCommunicable Diseases ad-hoc Working Group charged with the responsibility of moving this agenda forward.

\section{Introduction}

Non-communicable diseases (NCD, Table 1) account for $60 \%$ of all deaths and $44 \%$ of premature deaths $[1,2]$. NCD are now the greatest cause of morbidity and mortality even in developing countries where they account for twice as many deaths as HIV/AIDS, tuberculosis, malaria, and all other infectious diseases combined [1-3]. They are a barrier to achieving the UN's Millennium Development Goals [4] and are a global threat to our economies in addition to our health. A report by the World Economic Forum and Harvard University estimates that chronic disease, currently costing $2 \%$ of the global Gross Domestic Product (GDP), will cost the global economy 30 trillion \$US over the next two decades, cumulatively $48 \%$ of the global

J. P. A. Ioannidis

Department of Medicine, Stanford Prevention Research Center, Stanford University School of Medicine, Stanford, CA, USA

J. P. A. Ioannidis

Department of Health Research and Policy, Stanford University School of Medicine, Stanford, CA, USA

\section{J. P. A. Ioannidis}

Department of Statistics, Stanford University School of

Humanities and Sciences, Stanford, CA, USA

\section{K. M. Khan}

Department of Family Practice and School of Kinesiology and Centre for Hip Health and Mobility, The University of British Columbia, Vancouver, Canada

K. M. Khan

Aspetar: Qatar Orthopaedic and Sports Medicine Hospital, Doha, Qatar

R. Martinez

Design and Biology, IDEO, Boston, USA

W. van Mechelen

Department of Public and Occupational Health and EMGO Institute for Health and Care Research, VU University Medical Center, Amsterdam, The Netherlands
GDP in 2010 [3]. But, chronic diseases are largely preventable. Their main causes are related to lifestyle, i.e. physical inactivity (recently labeled by The Lancet as being pandemic [5]), an unhealthy diet, and tobacco and alcohol abuse.

In 2010, the World Health Organization (WHO) and the International Olympic Committee (IOC) signed a memorandum of understanding to jointly promote activities and policy choices designed to reduce the risk of NCD [6]. This was followed by a landmark speech given by the IOC President to the plenary session of the Sixty-Sixth General Assembly of the United Nations, September 19, 2011; a "watershed event" to "replace ignorance and inertia with awareness and right actions" [7]. IOC President Dr. Jacques Rogge told the Assembly: "The problem is acute, the solution is at hand. It is a grim picture, except for one thing: We can do something about it."

Low cost, highly effective solutions for the prevention and management of NCD are available [5]. The IOC President emphasized the WHO recommendations on physical activity as central to NCD prevention [6]. He called for safe and accessible public spaces for physical activity and sport, partnerships with transportation and urban planning, increased physical education and better sport infrastructure and organization, thus building on the comprehensive, broad-based, long-term approaches recommended by the International Society for Physical Activity and Health (ISPAH), the Grand Challenges Global Partnership, the WHO, the European Commission (EC),

W. van Mechelen

School of Human Movement Studies, University of Queensland, Brisbane, Australia

M. Mountjoy

Department of Family Medicine, Michael G DeGroote School of Medicine, McMaster University, Hamilton, Canada

R. E. Sallis

Department of Family Medicine, Fontana Medical Center, Kaiser Permanente Southern California, Fontana, USA

\section{J. Sundberg}

Department of Physiology and Pharmacology, Karolinska Institutet, Stockholm, Sweden

\section{R. Weiler}

Population Health Domain Physical Activity Research Group, Department of Epidemiology and Public Health, University College London, London, UK

R. Weiler

University College London Hospitals NHS Foundation Trust, London, UK 
Table 1 List of non-communicable diseases

Cardiovascular disease
Diabetes
Cancer
Chronic respiratory disease
Hypertension
Dyslipidemia
Obesity
Metabolic syndrome
Arthritis
Osteopenia/osteoporosis
Degenerative disc disease
Depression
Sarcopenia and frailty
Cognitive impairment
Cerebrovascular disease
Neurodegenerative disease
Rheumatoid arthritis

the World Economic Forum (WEF), Active Canada, Exercise is Medicine ${ }^{\mathrm{TM}}$, the Organization for Economic Cooperation and Development (OECD) [1-3, 8-13], and many others.

To date, efforts to promote a "home" for prevention within health care have largely failed. Waiting for comprehensive, emergent reform of dysfunctional health care systems is unrealistic. Likewise, results from reductionist research studies have not been successfully implemented and scaled in such a way as to create population-wide impact.

The current approaches to chronic disease prevention and management involving public health and global health strategy [14] may need to be merged with human-centered design (HCD). The latter approach, used as a catalyst for change in other industries, focuses on the importance of the human element in behavioural change [7]. Successful implementation of testable, novel approaches will require committed, visionary leadership willing to reframe the problem from a practical, human-design perspective while sticking to a clear strategy to mobilize the resources and capacities needed for change.

The objective of this IOC consensus meeting was to achieve alignment on a strategy to design a sustainable plan of action for the prevention and management of NCD, coupling existing scientific evidence with HCD, focusing particularly on physical activity/exercise and behavioural change. In order to accomplish this objective, the sport and exercise medicine (SEM) community must overcome considerable inertia created by the complexity and magnitude of the NCD problem and its context. The SEM community must bundle its efforts and embrace a new, creative approach aligned with a strategy that is clear, concrete, and human-centered.

\section{The Problem}

For most of human history, people needed to be physically active to survive. Today, for instance, only $20 \%$ of Norwegian [15], $8.2 \%$ of US [16], and $5 \%$ of UK [17] adults meet physical activity guidelines. Over a four-decade period, physical activity in the US has declined $32 \%$ and the reduction is projected to decline even further to $46 \%$ by 2030 [18], while from 1991 to 2009, China's physical activity rates dropped by $45 \%$ [18]. In the Arab World, eight countries have physical inactivity levels ranging from 33 to $70 \%$ of the population [19]. Over the past 50 years there has been a marked decline in energy expenditure for household management [20] and civilian occupation [21], sufficient to explain the rising prevalence of obesity [22]. Worldwide, physical inactivity and smoking are responsible for more deaths than any other modifiable risk factors [5]. Clinical scientists are continuing to identify more characteristics that magnify the problem. For example, sitting time has been shown to be associated with increased cardio-metabolic risk independent of levels of physical activity [23-25]. Low aerobic fitness is a risk factor for allcause mortality, cancer and cardiovascular disease, independent of body fatness [26, 27].

While the problem of physical inactivity, poor diet and unhealthy lifestyle behaviours is evident and clear, the real problem is that we have not been able to mitigate the steady rise in NCD. In fact, the morbidity and mortality from NCD has worsened during the time we have been accumulating research data and publishing position statements and recommendations [28]. The mere existence of national physical activity policies or action plans does not ensure their functionality or implementation. Physical activity guidelines are not implementation and implementation does not guarantee change [29]. We can no longer opine that governments, schools, employers, facility managers, urban planners, ministries of education, global organizations, health care professionals, universities, recreation and health departments, community organizations, sport federations, the health care system, and transportation departments, "should" do something [8]. The SEM community can $d o$ something, because its expertise lies closest to the intersection of physical activity, diet, and health.

Despite global advocacy for a sound "whole of government" systems approach [30], the direct and indirect costs of NCD remain staggering and unsustainable due to the financial, political and structural complexity involved. The health care industry pushes government agencies for policies leading to change and the government pushes the 
health care industry to develop programs of prevention. The failed attempt to limit the serving size of sugar-sweetened beverages by Mayor Bloomberg in New York City is an example of the limits of authority even with well-intended policy interventions [31]. In contrast, the Director of the Swedish Bureau of National Health and Welfare declared there is enough evidence $[32,33]$ for the health care system to act "now", an example of the government's expectation that real change requires the medical system to act. Prevention remains caught in the middle with policy makers telling health care to implement change and vice versa. With broad and ill-defined objectives that lack alignment and strategic focus, prevention remains in the realm of passive and suggestive theory and the vast amount of scientific evidence while true, has been useless for effecting change [34]. Not surprisingly, there is no clear plan to respond. We readily acknowledge the conflict between the complexity of chronic disease and the reductionist approach being used to solve it as well as the potential blind spots that result from determinist thinking $[35,36]$. The complex nonlinearity of health behaviour does not allow for simplification by solely focusing on a single intervention. We must resist, on the one hand, lofty position statements and recommendations that lack concreteness and clarity and that displace responsibility to amorphous entities and on the other hand, a top-down approach conceived by medical and scientific experts that reproduce knowledge and guidelines that does not translate into action.

We must figure out how to get around the obstacles that prevent us from making progress in prevention. These include: (1) the reductionist, determinist approach to thinking within medical science which has become the default approach to health care delivery, (2) the financial model of disease- and event-based medicine, (3) the single intervention model, (4) the lack of disease-burden matched and prevention-oriented curricula for training health care professionals, (5) the absence of a tailored distribution channel to deliver knowledge, and (6) the uncertainty of changing human behaviour [37].

\section{Methods}

In order to create a consensus action plan for the prevention and management of chronic disease, the IOC convened a group of experts April 10-12, 2013 in Lausanne representing SEM, public health, clinical epidemiology, design thinking, industry leadership, advocacy, exercise science, reliability and reproducibility of biomedical evidence, social marketing, education, technology, and lifestyle behaviour interventions. Prior to this, five participants met for one day in New York in December, 2012 to plan a design thinking approach to the meeting.
The $2 \frac{1}{2}$ day meeting opened with an introduction and statement of the problem followed by 15 minute lectures and discussion by each participant, addressing the following three questions: (1) Why did you accept the invitation to this meeting (why are you here)?, (2) What do you believe is the single most important thing that needs to happen (actually take place) to reduce the morbidity and mortality associated with chronic disease?, and (3) What steps would you take to implement that "thing" in the next one year? Experts were urged to use existing systematic collections of evidence as well as point to new areas of opportunity.

These presentations and discussions led the group to formulate the following issues for consideration: (1) the problem, (2) opportunities for behavioural change, (3) the importance of HCD, (4) the value of the SEM model of function and performance, (5) the requirement for actual centres within which to develop prevention programs, and (6) the importance of the IOC's leadership. Half the meeting time was spent using a design thinking approach to integrate scientific evidence with human reality to achieve consensus for an action plan. The last half-day was spent formulating a rough draft of the manuscript and an 18-month action agenda.

\section{Behavioural Change}

Given the impact of unhealthy lifestyles on the chronic disease pandemic [5, 16, 29] governments began, decades ago, to emphasize lifestyle and behaviour changes to broaden the scope of national health policies beyond traditional medical and surgical interventions [38-40]. For this reason, a primary focus on behavioural change as the core component of all clinical programs for the prevention and management of chronic disease is essential.

Understanding and guiding human behaviour is very complex given the wide range and overlapping correlation of individual (beliefs and attitudes), interpersonal (cultural and social norms), environmental (social, built and natural environment) and policy (regional, national and global) factors [16]. In a Swedish study, $76 \%$ of patients recognized responsibility for changing their own behaviour but still expected the health care system to help them change [41]. This complexity reflects the underlying discussion as to personal or social "responsibility" for physical inactivity and other lifestyle "choices".

The emphasis of interventions can be on proximal (individual) or more distal (social-cultural and/or environmental-political) correlates of physical inactivity and other lifestyle related behaviours. There is good reason to believe the proper emphasis is changing the environment by engineering physical activity into our daily lives without 
individual awareness. Insights such as the so called "nudges" encourage and support people through change toward a choice architecture that alters their behaviour in a predictable way, whilst fully preserving their autonomy and respecting cultural norms. In simple terms, nudging can be used to change the default option towards a healthier choice [42, 43], for example by placing healthier products at a more prominent and convenient place in the cafeteria. However, altering choice architecture through advocating for concurrent, system-wide strategies to build a supportive environment requires huge efforts to orchestrate multiple stakeholders including policy makers, non-governmental organizations (NGOs), schools and corporations to bring about desired changes.

Various social cognitive theories that solely emphasize the intention of self-regulation and self-control as key determinants of behaviour, eg. Theory of Reasoned Action [44] and Theory of Planned Behaviour [45] fall short when taking into account the importance of the habit formation process [46] and the contextual nature of behaviour [47]. Traditional interventions assume that people make rational lifestyle decisions whereas, in reality, many such decisions are actually irrational, using unreasoned shortcuts or heuristics (habits) instead of logic [48]. Thus, most interventions, which are designed solely from a content perspective without acknowledging the user as the expert of their own experience, are more likely to fail. Interventions and solutions need to "go with the grain of how people behave" [49].

The power of habit formation in behaviour counseling remains relatively untapped for NCD prevention. Habits are automatic responses to contextual cues, acquired through repetition of behaviour in the presence of these cues [50]. In order to change these habits one needs to take into account that a specific cue will trigger action if motivation and ability to perform the task are adequate to result in a physical or psychological reward [51]. For example, even if an unfit person becomes highly motivated to run a marathon tomorrow, he or she will most likely not succeed since the physical ability (e.g. cardiovascular capacity and muscular endurance) needs to be developed over time. Thus, the difficulty of the task needs to be lowered and thereby the ability to perform increased. Habit formation starts with simple, very specific tasks of daily physical activity that can be gradually increased as one builds confidence and control (e.g. taking the stairs instead of the elevator at work). With incremental success and the adoption of more ambitious behaviours, a more tractable and specific behaviour change is targeted rather than a complex task such as "running a marathon". Upon successful formation of one specific healthy habit in isolation, there may be a spillover effect to many other aspects of the individual's life
[52, 53]. Additionally, targeting one person with a behaviour change program may impact his or her social network by triggering substantial behaviour change in that person's friends, thereby shaping a social norm [52]. Thus, the cumulative impact of a preventive intervention is the sum of the direct health outcome of the individual, plus the collateral health outcomes in those socially connected (collateral health effects). This emphasizes the connection between the individual and surrounding social determinants of health [54]. Of course, collateral effects can be both positive and negative, and therefore both possibilities should be considered.

A large opportunity is appearing related to the conversion of data into information that helps guide sound decisions by both clinicians and patients. Tools like patient activation measures help to stratify and individualize patient care by tailoring coaching, education, prevention, and care protocols to different patients at different levels of readiness [55]. Technological advances are readily available, such as pedometers or tracking devices, that may include sensors in smartphones, to provide important information about individual physical activity patterns [56]. Persuasive technology uses interactive smartphone applications as a decision support tool to trigger certain user behaviours through instant feedback and support [51]. By incorporating the feedback from real-time patient data analysis, it is possible to provide insights in the choice architecture towards much more targeted behaviour counseling [51].

The explosion of big data produced by the digital society has caused a management revolution in other industries in decision-making and customer engagement $[57,58]$. Companies worldwide invest heavily in sophisticated analytical capabilities aiming to draw meaningful customer insights [56]. For example, traditional retailers analyze buying habits of their customers and run algorithms to better predict their needs and customize their product suggestions based on unique preferences of the individual [59]. In Public Health, Google is able to predict the spread of an influenza pandemic more accurately and several weeks earlier than the traditional surveillance systems of the US Centers for Disease Control (CDC) [60]. Comprehensive data analytics have long been used in sports such as baseball and soccer to determine success factors and adjust the tactics accordingly [61]. In health care, Electronic Medical Records (EMR) generate massive data sets, offering the challenge of how to convert largely unstructured by-products of health care delivery into useful assets for patients' insight [62]. These technology advances will leverage insights, foster behavioural change and ultimately lead to habit formation by influencing the individual, interpersonal or environmental factors, a necessity for a successful prevention plan. 


\section{Human-Centered Design}

In preventive health care we too often jump from our knowledge of a situation to "learned solutions", bypassing critically important steps including observing, discovering, interpreting, ideating, prototyping, iterating and monitoring. This works for many of our daily tasks (e.g. prescribing beta-blockers for high blood pressure) but reaches its limits with lifestyle change. For example, we don't always know how to translate precise, well-established guidelines and recommendations into an individual's daily routine [63]. Nor do we educate healthcare providers with the knowledge and skills to deliver well-established and evidence based interventions to our patients [64]. From a scientific, analytical perspective we know the doseresponse relationship of regular exercise with regard to frequency, duration and intensity [65]. In fact, every health care professional and layperson knows more or less about the importance of physical activity to well-being and quality of life. Still, the compliance rate with evidencebased guidelines is poor and inconsistent, from the provider and the patient perspective [63, 66].

Interventions designed from a content perspective that only see the user as the beneficiary of the final product or service often fail because, by directing people using a topdown approach, impediments for implementation and adherence at the individual and organizational level are not taken into account [67]. Patients are often given solutions that only focus on the treatment of their diseases instead of solutions that also incorporate aspects of desirability (Fig. 1). For example, prescribing a medication is one treatment option for many diseases, however, without a behavioural plan for habit formation, compliance may impede the success of this treatment option. When designing prevention programs, framing the context for behavioural change requires asking the right question, which is often "what matters most to you" rather than "what's the matter". The lack of active human engagement in understanding patients' underlying problems and developing feasible solutions may explain why, after decades of tool development, we haven't achieved results with prevention.

Yet "providing care that is respectful of and responsive to individual patient preferences, needs, and values and ensuring that patient values guide all clinical decisions" [68] has long been identified as a key quality improvement parameter towards patient-centered care [69-71]. Indeed, HCD has become an essential component within industry by providing tools to understand people's needs and motivations in order to design desirable, feasible, quality solutions that meet those needs [72-74].

Prevention differs from treatment from a behavioural perspective because future health problems are "invisible" (subclinical, asymptomatic) [75], resulting from deeply

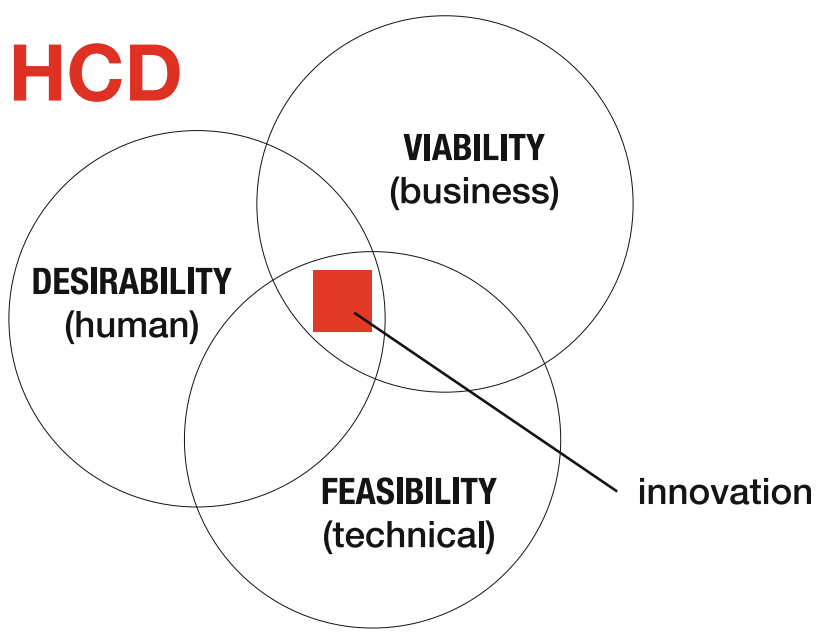

Fig. 1 Human-centred design (HCD) [72]. HCD is a methodology for innovation that requires engaging people in order to understand their preferences. With innovation, there are three overlapping constraints. Feasibility is what is functionally or technically possible within the foreseeable future. Viability is the likelihood the innovation will become part of a sustainable business model. Desirability refers to what makes sense to people and for people (important human factors). These constraints inspire innovation and an HCD approach will bring them into harmonious balance. Willing and even enthusiastic acceptance of competing constraints is the foundation of HCD. The design thinking process involves: (i) Understanding-challenging the status quo (too often we jump from ideas to solutions without understanding underlying motivators and drivers), (ii) observationgaining insights through on-site observations, (iii) synthesis-framing and grouping insights to identify problems and opportunities using visual techniques-it is critical to find the right question to ask because the way a problem is framed often identifies the approach to innovation, (iv) ideate-various approaches are used for innovation, and (v) prototype-rapid prototyping allows quick feedback for iterations

ingrained habits. With prevention, "success" is defined as the absence of an outcome (e.g. avoidance of a heart attack). Thus, empathic solutions become critically important in prevention. The challenge for health care, one that has not yet been embraced, is to accept responsibility for understanding the factors that direct behavioural change within this context. HCD embraces constraints to innovate solutions from the human perspective (Fig. 1) and combines empathy, creativity, and rationality in analyzing and fitting solutions to context and personal preferences. HCD uses techniques and methodologies to understand the complex context of internal motivators and external barriers to behavioural change and habit formation. Direct observation and interaction with people are used to understand the context of what they want and need in their lives and what they like or dislike about the way particular products or services are made and delivered (Fig. 1) [72]. By investigating - and designing for-the human element it is possible to gain unexpected insights on how to frame 
the problem from the individual's perspective in a way that can help to develop the sustainable solutions.

A design attitude toward problem solving allows us to ask basic, but fundamental questions like "what is the real problem being faced and how might we overcome it?" [76]. The initial solutions are created with human desirability in mind and focus later on the technical feasibility and viability of possible solutions [77]. For example, an increased attention to age appropriateness, fun, incentives and motivation, social support, feedback and style of teaching/coaching/ mentoring in interventions targeting children can be substantial to the experience and feeling of the intervention [78]. HCD is an approach that can incorporate other methodologies such as Intervention Mapping [79, 80] and that compensates for the deficiencies that require "implementation research" $[81,82]$. With these categories in hand, designing a simple and easily understandable program (more user-centric) avoids the confusion which often takes place at the end of program development when it's discovered that compliance with the intervention is low.

There is an immense opportunity arising as health care professionals show increased interest in focusing on usercentricity and acknowledge that designers can have a profound influence on social innovation [83]. The critical balance of creative and intuitive thinking (design thinking) with technical and content expertise (analytical thinking) has been very successful in diverse settings and organizations [72, 74]. Human-centered design with its inclination to action, rapid prototyping and multiple iterations can be piloted, scaled, and formally tested for its ability to create effective preventive programs for chronic disease.

\section{Unique Attributes of Sport and Exercise Medicine for Disease Prevention}

The modern medical discipline of SEM has its roots deeply imbedded in the scientific study of human function and the beneficial adaptations to physical activity and exercise that accrue in multiple organ systems. The human body has profound capacity to increase performance in response to training. Increases in muscle mass, stroke volume and ejection fraction, red blood cell mass, capillary density, mitochondrial volume density as well as changes in fuel storage and utilization result in improvements in muscle strength, endurance, aerobic and anaerobic capacity as well as agility, balance, and flexibility. These adaptations are profound. The term performance tends to be used to describe these adaptations in the competitive athlete while functional capacity is most often used for non-athletes. For an aged person or one with chronic disease and multiple co-morbidities, functional capacity remains trainable in the same way performance is trainable in athletes [84]. The training that results in these physiologic adaptations is the same training associated with substantial health benefits.

Despite this rather noble foundation for SEM, a clinical discipline less than four decades old, its potential to benefit health and function outside of competitive athletes has not been realized. For this reason, it is necessary to extend the knowledge and skills of SEM to the general population to build new programs for the prevention and management of chronic disease focused on physical activity, diet and other lifestyle components.

Virtually everyone develops chronic disease and most people develop multiple chronic diseases. For this reason, creating a culture of health versus disease is not realistic. The much more realistic approach is acknowledging the reality of chronic disease and working to prevent and manage it over the lifespan. Symptoms of chronic disease are simply events along a continuum that spans many years during which preventive practices may influence the onset and severity of the symptoms. Traditional medicine sees the absence of symptoms as health and the onset of disease symptoms as an acute event requiring treatment (e.g. medication or surgery). Prevention attempts to identify risk factors early, address these factors and thereby delay the onset of symptoms of chronic disease. Furthermore, prevention can ameliorate the effects of existing chronic disease on functional capacity and the development of related chronic diseases (co-morbidities).

There is an urgent challenge as to how to successfully include the prevention and management of chronic disease in the daily clinical practice of SEM and primary care medicine [37]. The challenge is one of addition-developing new capacity, clinical programs and expertise in chronic disease prevention and management to provide new preventive services to the general public in an effective and cost-effective way [85]. The focus of most SEM practitioners and clinics is still on the care of competitive athletes. One of the unique features of the scope of SEM is that, unlike other medical specialties, it is not organ system or disease specific [86]. To date, knowledge and clinical skills in the area of chronic disease prevention and management have not been the focus of continuing professional development in SEM even though this would be a relatively simple and potentially influential step to take. Formal clinical training in chronic disease prevention and management must be developed and provided for SEM and primary care practitioners that includes role identification, communication and integration between health care providers and the fitness and wellness industry.

\section{Creating Actual Programs and Centres for Disease Prevention}

Right now, there is no "home" for prevention within health care. There are no community-based prevention centres 
that can be directly accessed by anyone seeking to maintain or improve their health. Despite some existing rehabilitation facilities and lifestyle units in primary care, there are no programs of population-wide scale that focus on behavioural change with regards to physical activity, exercise or other lifestyle options. This vacuum is being filled by weight loss centres, fitness and wellness studios; a multi-billion dollar industry founded on principles that differ from those that underpin the health care industry. This results in a low level of interaction and coordination since the health care system tends to view these industries as lacking the "credibility" and "authenticity" to partner on prevention. To establish actual centres to design, implement, study, and improve preventive programs for chronic disease, the value provided by evidence-based medicine needs to be combined with the value provided by the fitness, wellness, and weight-loss industries with their action-oriented approach and wide distribution network.

The creation of a sustainable foundation for prevention requires actual, physical centres (Fig. 2). Initially, these could be pilot centres that meet robust criteria for the integration of evidence with human-centered design, the use of technology and the inclination to action and rapid prototyping. Several of these centers, with meaningful collaborations with health care, academia, industry and technology can serve as development sites. While there are a number of excellent, well-conducted studies of behavioural change using sound conceptual models, the current clinical approach tends to be an intuitive, trial-and-error process mostly relying on the experience and skills of individual practitioners and health coaches. The first centres would provide the structure for an ideal prevention program by fostering the seedbeds of behavioural design through understanding, observing, synthesizing, ideating, prototyping and iterating. The factor that determines success will be, first and foremost, the ability to meet the human needs that are currently "hidden behind" what is often viewed as more important (quantitative measurements of disease status) (Fig. 1). By starting with empathy and human desirability, the experience factors of the programs are built around the "job-to-be-done" for the individual behind the disease. Thus, an initial screening needs to include cognitive and behavioural assessments along with the traditional functional assessment.

The traditional grouping into primary, secondary and tertiary prevention holds value for health care providers, medical scientists and program development strategists concerned with population stratification, safety, programming, logistics and outcomes. However, categorizations such as these have little relevance to individuals entering a prevention program since they are remnants of reductionist thinking related to the presence or absence of disease or risk factors. Organizing programs around such categories falls short of acknowledging, amongst other things, the human elements that transcend the medical-biological origin of those prevention categories: namely personal interests, personality traits, temperament, skills and abilities. By thinking in disease categories, any prevention program subordinates its process and function to the stage and progression of a certain disease.

Likewise, it can be confusing if not overwhelming to determine what constitutes prevention vs. management of chronic disease. It is clear that prevention applies to those without disease or risk factors and management applies to those with chronic disease. But, this distinction is arbitrary and prevention, as an umbrella term, applies to behavioural change with or without the presence or absence of disease or risk factors. What matters most to people is that the program is desirable. That is the starting point.

In addressing the real needs of people, it is essential to identify certain persona profiles and characteristics of particular population groups. This helps to move from purely labeling people based on manifestations of disease toward valuing their needs and goals, which is the heart of prevention. Ninety percent of health care spending is for sicker patients with $80 \%$ of health care spending traced to patients with largely predictable health care needs and expenses: the chronically ill [87]. This bloated number is a mirror of our structures in medicine which are heavily tilted toward "fixing" disease. While tertiary prevention (management) might provide immediate gains from a costbenefit perspective, we must avoid the rigidity of categorization of prevention into primary, secondary and tertiary since this focuses the scope of service, yet again, on the reductionist model of type and stage of disease. Clinical, comprehensive lifestyle intervention programs bear substantial similarity with respect to the fundamental principles of behavioural design regardless of how a person is "labeled" or what category they are assigned. Any clinical program failing to recognize this by focusing on one prevention category only would fall short of creating true population-wide impact. For this reason we need to move from abstract concepts of prevention to concrete, relevant programs for groups of people, reflected in different personas, clustered according to their functional, behavioural and cognitive status. This approach, using factors that characterize human desirability for clustering and stratification is a key differentiation factor for the success of prevention programs. Alignment on this is absolutely essential.

The fundamental components of a prevention program include assessment (medical, cognitive, functional capacity, behaviour), program design and implementation, and monitoring and re-assessment (Fig. 2a). Individual components of the program must be based on evidence and current guidelines and delivered by trained health care 
a

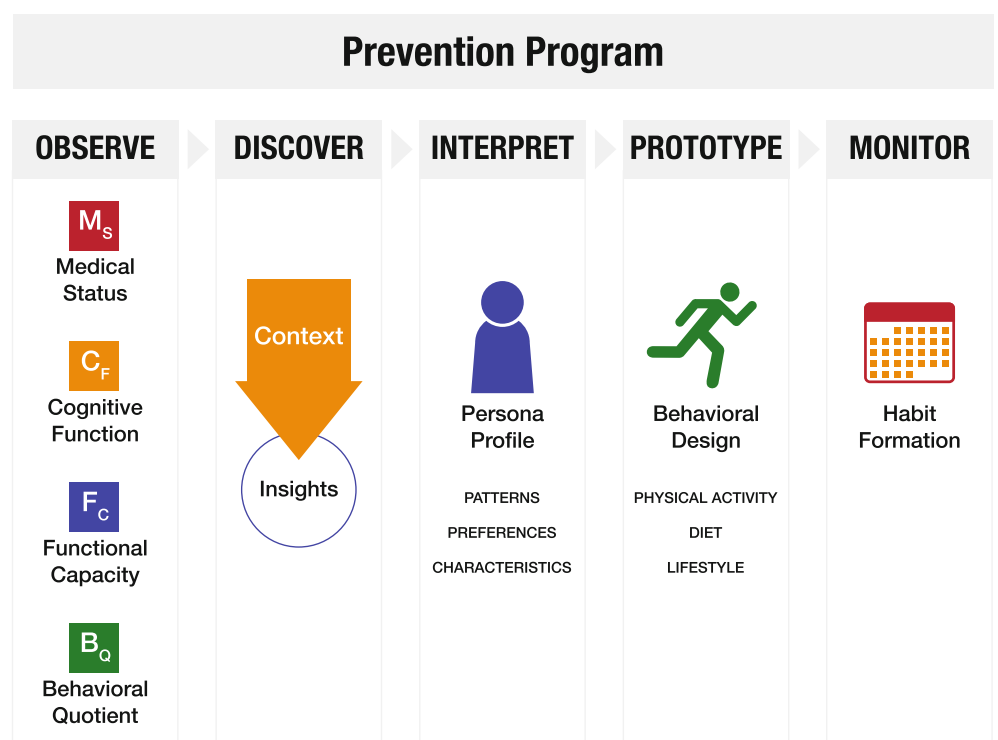

b

Community Prevention Centers

standardize, license, scale for population-wide impact

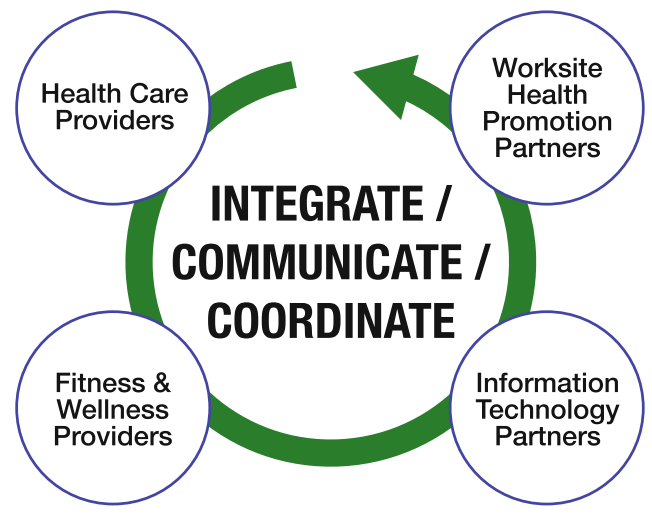

Fig. 2 Community Prevention Centres (CPCs). CPCs are actual facilities where scientific evidence-based medicine and humancentered design (HCD) are combined to develop and implement prevention programs. While much of the interdisciplinary interaction remains to be precisely defined, the road map shown integrates the HCD approach with the traditional method of program development. a In the initial observation phase of the prevention program, the medical status $\left(M_{\mathrm{S}}\right)$ of each client is assessed as well cognitive function $\left(C_{\mathrm{F}}\right)$, functional capacity $\left(F_{\mathrm{C}}\right)$, and behavioural quotient $\left(B_{\mathrm{Q}}\right)$. This input assists the health care professional in observing and understanding the context of the individual's current situation and generates insights regarding possibilities for behavioural change. Interpreting and synthesizing these insights and contexts enables the development of archetypal personas that can be used to classify client services based on key characteristics that relate to the likelihood of success for certain interventions. Based upon the experience and history with certain persona profiles, the health care professional can engage the client in an ideation process to target healthier behavior. Single, achievable tasks that result in behavioural change are used as prototypes for iterations that build confidence and control. The evolving loop of habit formation is dynamic and non-linear. Monitoring by e-Health tools includes measurement of outcomes in addition to reassessment. b CPCs integrate, communicate and coordinate client experience within an ecosystem that includes health care providers, fitness and wellness providers, worksite health promotion partners, and information technology partners. This communication, coordination and integration is critically important to bridge CPCs with existing structures in order to provide the client with an integrated service. Close medical follow-up and communication is especially important for chronically ill patients. The ideal setting for initial development and testing of these programs is in dedicated research centers that meet robust criteria for collaboration and feasibility. The specifics of such programs will shape over time with the help of data analytics such that the initially intuitive process will become a more standardized, precise way of behavioural change design. By achieving that, the program will become more affordable and it will be possible to achieve scale through, for example, licensing agreements to other health care providers or fitness facilities 
professionals with experience and expertise. Much of this remains to be developed. Functional capacity includes all the factors that correlate with the physical ability to perform a given task. Behavioral quotient is a set of attributes that indicate motivation such as the readiness for change [88]. Cognitive function refers to information processing and learning. These four sets of factors shape the structure of a prevention program. In aggregation these variables and attributes contribute to a set of differing persona profiles. Upon taking into account the different preferences from various perspectives of personal development, programs can be much better designed to fit personal needs. Thus, using factors that characterize human desirability for clustering and stratification is a key differentiation factor for the success of prevention programs (Fig. 2a).

Based upon these assessment results and persona profiles, a program can be designed and customized to meet the individual's goals. Multiple options for health-related data exist (e.g. EMR, physical activity tracking devices, purchase histories, social media profiles), that can help in stratifying at the population level and later at the individual level to support rational decision making [48]. The evergrowing patient throughput in pilot programs of prevention will generate a large database and hands-on experience that can help to identify patterns at the population level allowing prediction in probabilistic terms of what works for whom under which circumstances. This would formalize the currently intuitive, informal process of providing behavioural change advice by health care professionals and move prevention toward a precise and personalized approach of mass customization. As a result, standardized yet individualized programs of high quality and low cost could be scaled at the population level.

\section{Growing and Scaling Prevention Programs and Centres}

At the core of the development of prevention and programs and centres is the creation of value for patients and caregivers through human-centred design (desirability, Fig. 1). Likewise, a sound business model is necessary in order to scale programs and generate population-wide impact (viability, Fig. 1). A strong partnership between the global SEM and primary care communities, sport federations and National Olympic Committees (NOCs) can mobilize resources and leverage networks to scale and distribute prevention programs (feasibility, Fig. 1). Working within these three constraints; desirability, viability and feasibility provides the greatest chance for innovation in prevention.

Progress in chronic disease prevention and management will require exceptionally strong leadership, a willingness to be disruptive [89] and a focus on rapid innovation.
Success will require a deliberate, systematic approach with strategy clearly and continuously mapped to mission and vision, and resources developed to create capacity.

Sport and exercise have an important role to play in the prevention and management of non-communicable diseases $[85,90]$ and the IOC is the natural leader in this area [91]. Both the International Federations and the National Olympic Committees can play an integral role in promoting physical activity through sport by partnering with the IOC, WHO, International Physical Activity Networks, SEM associations and NGOs [92]. Many countries now focus on leaving a legacy of improving the health of the population by increasing physical activity as part of hosting major sporting events such as the Olympic and Paralympic Games [93, 94].

The IOC has already demonstrated its leadership capability in the establishment of programs such as Sport for All [95], Olympic Day Celebrations [96, 97], IOC Medical Commission initiatives such as health and fitness for young people through physical activity and sports [98] and education programs [99-101], the Youth Olympic Games [102], and through its collaboration with the WHO [6] and the UN [7]. The Olympic Games and the Olympic brand itself are based on positive universal values, which give it a powerful, emotive and unique identity that transcends sport and resonates strongly with people of all ages and cultures from around the world [103]. Olympic athletes inspire people to be the best they can in their everyday lives. Corporate partnerships build on this inspiration in causerelated marketing campaigns, which helps companies build socially responsible images and brand affinity within their customer base, translating into higher brand memorability, preference, and purchasing.

These partners are in a mutually beneficial, synergetic relationship with the IOC, which operates as a non-profit organization. There is a great opportunity to promote an IOC accredited prevention program through an alliance with well-known and respected corporate partners and medical societies and academic groups in order to penetrate and persuade a massive customer base [104]. The facilities and distribution channels already exist through the SEM and primary care networks. Upon developing successful and cost-effective prevention programs with adapted but stable financial models, these programs can be scaled internationally to lead to widespread change toward prevention.

The IOC, as a governing body, will continue its shared commitment and partnership with the SEM community by initiating and sustaining its effort toward the prevention of chronic disease, using a framework for change of the type described by Kotter (Table 2) [105, 106]. Some of the IOC's activities will include new and innovative methods like design thinking, which will require autonomy and 
Table 2 Kotter's 8-step change model for leadership (modified from Kotter [106], with permission)

1. Establish a sense of urgency

2. Create a guiding coalition

3. Develop a vision for change

4. Communicate the vision for buy-in

5. Empower broad-based action

6. Generate short-term wins

7. Never let up-build on the change

8. Incorporate changes into the culture

appropriate opportunity for creative work, while others will foster collaboration, diversity and integration, maintaining the respect for traditions.

While it remains essential for the IOC, given its political influence, to advocate for a multifaceted approach [1-3, 8 , $11]$ and to collaborate with policy makers, NGOs, schools, and corporations [107, 108], it is critical for the IOC to focus on one goal in the present to prevent the overwhelming paralysis that occurs when trying to simultaneously balance all public health issues at once. What is true for the individual, applies to organizations as well: "you can eat an elephant, but only one bite at a time". The IOC will work with the SEM community on the primary goal of designing clinical lifestyle intervention tools for health care professionals to adequately direct and assist patients in behaviour change. Given the talent, knowledge and resources within the IOC and the vested interest of the SEM community, the influence of this partnership, focused on the individual, has the potential to be immense.

The creation of prevention centres permits the leadership to pursue one clear strategy, a simple, immediate, and amenable method of influence from within health care that will have population wide impact. These centres will incorporate evidence with the systematic application of design thinking alongside current health promotion principles. In order to gain support and bring to life ideas, which are currently abstract (such as behavioural change) grass roots pilot projects with an inclination to rapid prototyping are required. This will raise aspirations and inspire action in skeptics. Thus, it is critical to identify a core group of early supporters and strategic key stakeholders with personal passion, enthusiasm, and commitment, ready to defer conventional judgment and express their willingness to stimulate breakthrough ideas.

Initial prototyping and experimentation is likely to take place in the clinical setting. However, upon development of a working program, its success depends on its distribution and scale. Thus, it is important to successfully transfer such programs to primary care, the workplace, wellness initiatives [3, 109], and the fitness industry. This can take place through licensing agreements transferring content, skills and expertise to interested health care professionals in order to create a network of branded prevention centres (Fig. 2b).

Training and education are critically important components for the development of future professionals working in the field of disease prevention and management. Currently, there is no single group of health care professionals that possess the full spectrum of knowledge and skills required for clinical work in disease prevention [64, 110]. Various components are fragmented between physicians, fitness experts, physical therapy, nursing, exercise physiologists (kinesiologists) and other professions [2]. Coordination of the development of curricula, training, and certification between and within these professions is essential. The IOC-SEM partnership has the ability to certify practitioners in prevention and management. Given the new approach to open-learning [99-101, 111, 112] resources could be made available globally, providing immediate and wide distribution and scaling. For example, the IOC has developed a 2-year diploma program in nutrition and sports medicine [99-101], but could move a step further toward integrating the prevention scholar into a network of prevention centres operating under accreditation standards. The idea is to move beyond education, training and skill development to provide essential frameworks of sound business models that allow the practice of prevention within the health care system.

This will further generate momentum for a renewed commitment to prevention even within traditional health care stakeholders. The under-representation of comprehensive lifestyle intervention, including physical activity in the curricula of medicine [113] and other health professions [64] will be addressed more efficiently, when sound and reasonable alternatives like an IOC accredited prevention program are ready at hand.

\section{Conclusion}

The IOC Working Group on NCD aims to establish a road map for change that respects both evidence and innovation through human-centred design. While supporting large, long-term visions that require coordinated, massive and complex political and systemic shifts, the IOC will pursue an active role with a vision focused on providing services to individual patients. Our current health care systems, with their reductionist underpinnings, can only respond awkwardly to the notion that a disruptive approach is urgently needed if we are to be successful in stemming the tide of preventable chronic disease. The issues are not those of more research and scientific evidence, sufficient funding, or health care restructuring. The issue is one of in-action, 
on the one hand, and grandiose plans on the other, in the midst of an overwhelming problem and resistance to change. Creative solutions are available, beginning with evidence-based, human-centred programs to provide preventive services immediately. Leadership is the key.

Acknowledgments No sources of funding were used to assist in the preparation of this article. The authors have no potential conflicts of interest that are directly relevant to the content of this article.

Conflict of interest The authors of the IOC paper on NCD prevention declare no conflicts of interest.

\section{References}

1. Daar AS, Singer PA, Persad DL, et al. Grand challenges in chronic non-communicable diseases. Nature. 2007; 450(7169):494-6.

2. Global status report on noncommunicable diseases 2010. World Health Organization, editor. 2011.

3. Bloom DE, Cafiero ET, Jane-Llopis E, et al. The global economic burden of non-communicable diseases. Geneva: World Economic Forum; 2011.

4. Fuster V. Cardiovascular disease and the UN millennium development goals: a serious concern. Nature Clin Pract Cardiovasc Med. 2006;3(8):401.

5. Lee IM, Shiroma EJ, Lobelo F, et al. Effect of physical inactivity on major non-communicable diseases worldwide: an analysis of burden of disease and life expectancy. Lancet. 2012;380(9838):219-29.

6. Rogge J. High-level meeting of the UN General Assembly on the Prevention and Control of Non-communicable Diseases: statement by Dr. Jacques Rogge, President of the IOC. In: United Nations, editor. New York: United Nations; 2011.

7. Non-communicable Diseases Deemed Development Challenge of "Epidemic proportions" in Political Declaration Adopted During Landmark General Assembly Summit. In: Department of Public Information United Nations, editor. New York: United Nations; 2011.

8. Active Canada 20/20. A physical activity strategy \& change agenda for Canada creating a culture of an active nation. 2012.

9. NICE public health guidance. Promoting physical activity in the work place. In: Excellence NIfHaC, editor. UK: National Institute for Health and Clnical Excellence; 2008.

10. Sassi F, Hurst J. The prevention of lifestyle-related chronic diseases: an economic framework. In: Development OfEC-oa, editor. Paris: OECD Health Working Papers; 2008.

11. Non communicable disease prevention: investments that work for physical activity. British J Sports Med. 2011;46:709-12.

12. Exercise is Medicine. The Global Initiative. 2008. http:// exerciseismedicine.org/global.htm.

13. EU Working Group "Sport \& Health". EU physical activity guidelines: recommended policy actions in support of healthenhancing physical activity. Brussels: Bundesministerium; 2008.

14. Rose G. The strategy of preventive medicine. Oxford: Oxford University Press; 1992.

15. Nordic Nutrition Recommendations 2004, 2005. http://www. norden.org/en/publications/publikationer/2004-013.

16. Bauman AE, Reis RS, Sallis JF, et al. Correlates of physical activity: why are some people physically active and others not? Lancet. 2012;380(9838):258-71.
17. Chapter 6: Accelerometry in children. In: Craig R, Mindell J, Hirani V, editors. Health Survey for England 2008: physical activity and fitness. Leeds: Health and Social Care Information Centre; 2009. p. 160-73.

18. Ng SW, Popkin BM. Time use and physical activity: a shift away from movement across the globe. Obesity Rev Off J Int Assoc Study Obesity. 2012;13(8):659-80.

19. Lim SS, Vos T, Flaxman AD, et al. A comparative risk assessment of burden of disease and injury attributable to 67 risk factors and risk factor clusters in 21 regions, 1990-2010: a systematic analysis for the Global Burden of Disease Study 2010. Lancet. 2013;3(380):2224-60.

20. Archer E, Shook RP, Thomas DM, et al. 45-year trends in women's use of time and household management energy expenditure. PLoS ONE. 2013;8(2):e56620.

21. Church TS, Thomas DM, Tudor-Locke C, et al. Trends over 5 decades in U.S. occupation-related physical activity and their associations with obesity. PLoS ONE. 2011;6(5):e19657.

22. Hill JO, Peters JC. Environmental contributions to the obesity epidemic. Science. 1998;280(5368):1371-4.

23. Healy GN, Eakin EG, Lamontagne AD, et al. Reducing sitting time in office workers: short-term efficacy of a multicomponent intervention. Prev Med. 2013;57(1):43-8.

24. Dunstan DW, Thorp AA, Healy GN. Prolonged sitting: is it a distinct coronary heart disease risk factor? Curr Opin Cardiol. 2011;26(5):412-9.

25. Owen N, Healy GN, Matthews CE, et al. Too much sitting: the population health science of sedentary behavior. Exerc Sport Sci Rev. 2010;38(3):105-13.

26. Lee DC, Sui X, Church TS, et al. Changes in fitness and fatness on the development of cardiovascular disease risk factors hypertension, metabolic syndrome, and hypercholesterolemia. J Am Coll Cardiol. 2012;59(7):665-72.

27. Bacon L, Aphramor L. Weight science: evaluating the evidence for a paradigm shift. Nutr J. 2011;10:9.

28. Remington PL, Brownson RC, Centers for Disease Control Prevention. Fifty years of progress in chronic disease epidemiology and control. Morb Mortal Wkl Rep Surveill Summ. 2011;60 (Suppl 4):70-7.

29. Kohl HW, Craig CL, Lambert EV, et al. The pandemic of physical inactivity: global action for public health. Lancet. 2012;380(9838):294-305.

30. Sacks G, Swinburn BA, Lawrence MA. A systematic policy approach to changing the food system and physical activity environments to prevent obesity. Aust N Z Health Policy. 2008;5:13.

31. Mariner WK, Annas GJ. Limiting "sugary drinks" to reduce obesity—who decides? N Engl J Med. 2013;368:1763-5.

32. National guidelines for methods of preventing disease. Sweden: Swedish National Board of Health and welfare; 2011. http:// www.socialstyrelsen.se.

33. Physical activity in the prevention and treatment of disease. Stockholm: Swedish National Institute of Public Health, Professional Associations for physical activity; 2010. http://www. fyss.se.

34. Heath C, Heath D. Switch: how to change things when change is hard. New York: Broadway Books; 2010.

35 . Heng HHQ. The conflict between complex systems and reductionism. JAMA. 2008;300(13):1580-1.

36. Federoff HJ, Gostin LO. Evolving from reductionism to holism: is there a future for systems medicine? JAMA. 2009;302(9): 994-6.

37. Matheson GO, Klugl M, Dvorak J, et al. Responsibility of sport and exercise medicine in preventing and managing chronic disease: applying our knowledge and skill is overdue. British $\mathbf{J}$ Sports Med. 2011;45(16):1272-82. 
38. Healthy people: the Surgeon General's report on health promotion and disease prevention. In: United States, Public Health Service, Office of the Surgeon General and Office of the Assistant Secretary for Health, editor. 1979. p. 262.

39. Lalonde M. A new perspective on the health of Canadians: a working document. Ottawa: Minister of Supply and Services Canada, Government of Canada; 1974.

40. Great Britain, Dept. of Health and Social Security; Northern Ireland, Dept. of Health and Social Security. Prevention and health: everybody's business: a reassessment of public and personal health. London: Majesty's Stationery Office; 1976.

41. Leijon M, Stark-Ekman D, Nilsen P, et al. Is there a demand for physical activity interventions provided by the health care sector? Findings from a population survey. BMC Publ Health. 2010;10:34

42. Sunstein CR. Empirically informed regulation. Univ Chicago Law Rev. 2011;78:1349.

43. Thaler DS. Improving introspection to inform free will regarding the choice by healthy individuals to use or not use cognitive enhancing drugs. Harm Reduct J. 2009;6:10.

44. Sheppard BH, Hartwick J, Warshaw PR. The theory of reasoned action: a meta-analysis of past research with recommendations for modifications and future research. $\mathrm{J}$ Consum Res. 1988;15(3):325-343.

45. Ajzen I. The theory of planned behavior. Organ Behav Hum Decis Process. 1991;50:179-211.

46. Aarts H, Paulussen T, Schaalma H. Physical exercise habit: on the conceptualization and formation of habitual health behaviours. Health Educ Res. 1997;12(3):363-74.

47. Kremers SP, de Bruijn GJ, Visscher TL, et al. Environmental influences on energy balance-related behaviors: a dual-process view. Int J Behav Nutr Physical act. 2006;3:9.

48. Kahneman D. Thinking, fast and slow. 1st ed. New York: Farrar, Straus and Giroux; 2011.

49. Behavioural Insights Team. Behavioural Insights Team Annual Report 2010-2011. In: Cabinet Office, editor. London, UK: Crown; 2011.

50. Nilsen P, Roback K, Broström A, et al. Creatures of habit: accounting for the role of habit in implementation research on clinical behaviour change. Implement Sci. 2012;7:53.

51. Fogg BJ. Creating persuasive technologies: an eight-step design process. In: 4th international conference on persuasive technology. New York: ACM; 2009.

52. Christakis NA, Fowler JH. Social contagion theory: examining dynamic social networks and human behavior. Stat Med. 2013;32(4):556-77.

53. Blair SN, Jacobs DR Jr, Powell KE. Relationships between exercise or physical activity and other health behaviors. Publ Health Rep. 1985;100(2):172-80.

54. Centola D. The spread of behavior in an online social network experiment. Science. 2010;329(5996):1194-7.

55. Hibbard JH, Greene J. What the evidence shows about patient activation: better health outcomes and care experiences; fewer data on costs. Health Aff. 2013;32(2):207-14.

56. Committee on Depicting Innovation in Information Technology, Computer Science and Telecommunications Board, Division on Engineering and Physical Sciences NRC. Continuing innovation in information technology. Washington: The National Academies Press; 2012.

57. McAfee A, Brynjolfsson E. Big data: the management revolution. Harv Bus Rev. 2012;90(10):60-6, 8, 128.

58. Brynjolfsson E, Hitt LM, Kim HH. Strength in numbers: how does data-driven decisionmaking affect firm performance? Soc Sci Res Netw. 2011. http://ssrn.com/abstract=1819486 or http:// dx.doi.org/10.2139/ssrn.1819486.
59. Duhigg C. How companies learn your secrets. New York Times, 2012 Feb. 16.

60. Ginsberg J, Mohebbi MH, Patel RS, et al. Detecting influenza epidemics using search engine query data. Nature. 2009;457(7232):1014.

61. Wolfe R, Wright PM, Smart DL. Radical HRM innovation and competitive advantage: the Moneyball story. Hum Res Manag. 2006;45(1):111-45.

62. Murdoch TB, Detsky AS. The inevitable application of big data to health care. JAMA. 2013;309(13):1351-2.

63. Weiler R, Feldschreiber P, Stamatakis E. Medicolegal neglect? The case for physical activity promotion and exercise medicine. British J Sports Med. 2012;46(4):228-32.

64. Weiler R, Chew S, Coombs N, et al. Physical activity education in the undergraduate curricula of all UK medical schools: are tomorrow's doctors equipped to follow clinical guidelines? British J Sports Med. 2012;46(14):1024-6.

65. Swedish National Institue of Public Health. Physical activity in the prevention and treatment of disease, Stockholm, Sweden. 2010. http://www.fyss.se.

66. Douglas F, Torrance N, van Teijlingen E, et al. Primary care staff's views and experiences related to routinely advising patients about physical activity. A questionnaire survey. BMC Publ Health. 2006;6:138.

67. Bodenheimer T, Lorig K, Holman H, et al. Patient self-management of chronic disease in primary care. JAMA. 2002;288(19):2469-75.

68. Kierkegaard S, Lowrie W. The point of view, etc: including The point of view for my work as an author, two notes about 'the individual' and on my work as an author. London: Oxford University Press; 1939.

69. Berwick DM. What 'patient-centered' should mean: confessions of an extremist. Health Aff. 2009;28(4):555-65.

70. Berwick DM. A primer on leading the improvement of systems. BMJ. 1996;312(7031):619-22.

71. Crossing the quality chasm: a new health system for the 21 st century. In: Institute of Medicine, editor.USA: National Academy Press; 2001.

72. Brown T. Change by design: how design thinking can transform organizations and inspire innovation. 1st ed. New York: HarperCollins Publishers; 2009.

73. Luma Institute L. Innovating for people: handbook for humancentered design methods. USA: Luma Institute, LLC; 2012.

74. Martin RL. The design of business: why design thinking is the next competitive advantage. Boston: Harvard Business Press; 2009.

75. Gordon J. Beyond knowledge: guidelines for effective health promotion messages. J Ext. 2002;40(6):e6FEA7.

76. Boland R, Collopy F. Managing as designing. Stanford: Stanford business books; 2004.

77. Hall A. Experimental design: design experimentation. Des Issues. 2011;27(2):17-26.

78. Design to move: a physical activity action agenda. Beaverton: Nike Inc.; 2012.

79. Kok G, Mesters I. Getting inside the black box of health promotion programmes using intervention mapping. Chronic Illn. 2011;7(3):176-80.

80. Kok G, Schaalma H, Ruiter RA, et al. Intervention mapping: protocol for applying health psychology theory to prevention programmes. J Health Psychol. 2004;9(1):85-98.

81. Finch CF, Donaldson A. A sports setting matrix for understanding the implementation context for community sport. British J Sports Med. 2010;44(13):973-8.

82. Donaldson A, Finch CF. Sport as a setting for promoting health. British J Sports Med. 2012;46(1):4-5. 
83. Tromp N, Hekkert P, Verbeek P-P. Design for socially responsible behavior: a classification of influence based on intended user experience. Des Issues. 2011;27(3):3-19.

84. Investigators LS, Pahor M, Blair SN, et al. Effects of a physical activity intervention on measures of physical performance: Results of the lifestyle interventions and independence for Elders Pilot (LIFE-P) study. J Gerontol Ser A Biol Sci Med Sci. 2006;61(11):1157-65.

85. Jones NSC, Weiler R. SEM: a fresh approach NHS information document. 2011. http://www.northwest.nhs.uk/document_uploads/ 2012/Sport-and-Exercise-Medicine-A-Fresh-Approach.pdf.

86. McCrory P. What is sports and exercise medicine? British $\mathrm{J}$ Sports Med. 2006;40(12):955-7.

87. Thorpe KE. The rise in health care spending and what to do about it. Health Aff. 2005;24(6):1436-45.

88. Prochaska JO, Velicer WF, Rossi JS, et al. Stages of change and decisional balance for 12 problem behaviors. Health Psychol Off J Div Health Psychol Am Psychol Assoc. 1994;13(1):39-46.

89. Darzi A, Beales S, Hallsworth M, et al. The five bad habits of healthcare: how new thinking about behaviour could reduce health spending. In: World Economic Forum, editor. London; 2011.

90. Mountjoy M. Health and fitness of young people: what is the role of sport? British J Sports Med. 2011;45(11):837-8.

91. Olympic Congress 2009 Copenhagen Recommendation \#51, Recommendations of Theme: 'Olympism and Youth'. Copenhagen: XIII Olympic Congress; 2009.

92. Micheli L, Mountjoy M, Engebretsen L, et al. Fitness and health of children through sport: the context for action. British J Sports Med. 2011;45(11):931-6.

93. Tew GA, Copeland RJ, Till SH. Sport and exercise medicine and the olympic health legacy. BMC Med. 2012;10:74.

94. Black ME. An olympic legacy for couch potatoes? BMJ. 2012;345:5578.

95. International Olympic Committee. Sport for all Lausanne, Switzerland. 2000. http://www.olympic.org/Documents/ Reports/EN/en_report_26.pdf.

96. Khan KM, Thompson AM, Blair SN, et al. Sport and exercise as contributors to the health of nations. Lancet. 2012;380(9836):59-64.

97. International Olympic Committee. What is olympic day? Lausanne, Switzerland. 2013. http://www.olympic.org/ioc?articlenews group=-1\&articleid=199903.

98. Mountjoy M, Andersen LB, Armstrong N, et al. International Olympic Committee consensus statement on the health and fitness of young people through physical activity and sport. British J Sports Med. 2011;45(11):839-48.

99. International Olympic Committee. IOC diploma in sports nutrition, Lausanne, Switzerland. 2013.

100. International Olympic Committee. IOC diploma in sports medicine. 2013.

101. International Olympic Committee. Education through sport. Lausanne, Switzerland. 2013. http://www.olympic.org/content/ olympism-in-action/education-through-sport/.

102. International Olympic Committee. YOG news: what is YOG? Lausanne, Switzerland. 2013. http://www.olympic.org/news/ what-is-yog/195805.

103. International Olympic Committee. IOC marketing: media guide. London, Lausanne, Switzerland. 2012. http://www.olympic.org/ Documents/IOC_Marketing/London_2012/IOC_Marketing_ Media_Guide_2012.pdf.

104. Berglinda M, Nakata C. Cause-related marketing: more buck than bang? Bus Horizons. 2005;48(5):443-53.

105. Kotter J. Leading change: why transformation efforts fail. Harv Bus Rev. 2007:96-103.

106. Kotter International. 2013. http://www.kotterinternational.com.

107. Wierenga D, Engbers LH, van Empelen P, et al. The design of a real-time formative evaluation of the implementation process of lifestyle interventions at two worksites using a 7-step strategy (BRAVO@Work). BMC Publ Health. 2012;12:619.

108. de Meij JS, Chinapaw MJ, van Stralen MM, et al. Effectiveness of JUMP-in, a Dutch primary school-based community intervention aimed at the promotion of physical activity. British J Sports Med. 2011;45(13):1052-7.

109. Carnethon M, Whitsel LP, Franklin BA, et al. Worksite wellness programs for cardiovascular disease prevention: a policy statement from the American Heart Association. Circulation. 2009;120(17):1725-41.

110. Weiler R, Murray A, Joy E. Do all health care professionals have a responsibility to prescribe and promote regular physical activity: or let us carry on doing nothing. Curr Sports Med Rep. 2013;12(4):272-5.

111. Stanford University. Stanford online. 2013. http://online. stanford.edu/courses.

112. Carnegie Mellon University. Open learning initiative. 2013. http://oli.cmu.edu/learn-with-oli/see-our-free-open-courses/.

113. Jaques R, Loosemore M. Sports and exercise medicine in undergraduate training. Lancet. 2012;380(9836):4-5. 